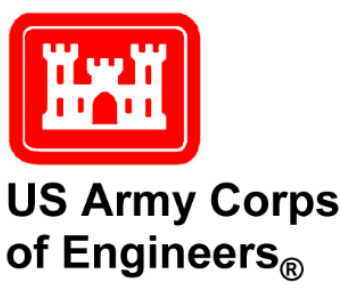

\title{
AIS Data: Real-Time Operation Support, Incident Investigations, and Waterway Use Analysis
}

by Marin M. Kress, Brian J. Tetreault, Kenneth N. Mitchell, Matthew T. Balazik, and Michael C. Booton

PURPOSE: This Coastal and Hydraulics Engineering Technical Note (CHETN) presents examples of Automatic Identification System (AIS) data and capabilities used to support real-time operations, assist in incident investigations, and contribute to waterways usage analysis projects for a variety of infrastructure management needs across the US Army Corps of Engineers (USACE). These case study presentations serve as examples for those who are new to AIS technology or navigation infrastructure operations.

INTRODUCTION: The development of AIS technology for ocean-going vessels was active in the 1990s, but implementation became more widespread after the year 2001. By 2016, carriage requirements had expanded to include most commercial self-propelled vessels on US navigable waters including any vessel over $65 \mathrm{ft}^{1}$ in length, towing vessels over $26 \mathrm{ft}$ in length with a greater than $600 \mathrm{hp}$ engine, vessels certified to carry 150 or more passengers, dredges in or near a commercial channel, and vessels moving certain dangerous cargo (USCG 2018; US Code of Regulations 2019). In addition, many private recreational vessels have also chosen to carry AIS transceivers to improve on-water awareness. Beyond the improved situational awareness for mariners that real-time AIS provides, historical AIS records have proven useful to a variety of maritime stakeholders, including infrastructure operators (Mitchell and Scully 2014; Scully and Mitchell 2015). AIS vessel position data can be purchased through commercial vendors or received from the US Coast Guard (USCG) Nationwide AIS (NAIS) archive. Two software programs developed by the US Army Engineer Research and Development Center (ERDC) have access to AIS data feeds and make AIS data available to USACE personnel. These programs are the Lock Operations Management Application (LOMA) (USACE-ERDC 2017) and the AIS Analysis Package (AISAP) (USACE-ERDC 2018), both described in the next section. Further information about AIS technical standards and history can be found online through international associations involved in setting technical standards (IALA 2008; IEC 2001; ITU-R 2014; PIANC 2019). This CHETN will describe how AIS data have been applied across the USACE in the areas of real-time waterway operations, incident investigations, and waterway use analysis.

\section{METHODS}

Lock Operations Management Application (LOMA). LOMA is a web-based tool designed primarily for real-time operational use by infrastructure operators, primarily at navigation locks. LOMA presents AIS data in a graphic user interface in conjunction with electronic charts, aerial imagery, and other information.

\footnotetext{
${ }^{1}$ For a full list of the spelled-out forms of the units of measure used in this document, please refer to US Government Publishing Office Style Manual, 31st ed. (Washington, DC: US Government Publishing Office, 2016), 248-52, https://www.govinfo.gov/content/pkg/GPO-STYLEMANUAL-2016/pdf/GPO-STYLEMANUAL-2016.pdf.
} 
LOMA receives data from the USACE network of over 135 AIS transceivers located along inland waterways, as well as nine USACEowned vessels. Data from the LOMA network are ultimately sent to the NAIS archive for longterm storage. A view of the LOMA user interface is shown in Figure 1. LOMA access is currently available to any USACE employee.

AIS Analysis Package (AISAP). AISAP is a web-based software that allows users to query the USCG NAIS archive of AIS records. AISAP users can search for individual vessels or do a spatial search for all vessels that transited a defined area within a given time range. Data queries can be customized in a variety of ways, including by the signal sampling frequency (e.g., every 2 s or once per day), vessel speed range, or vessel types. Once data are acquired from the NAIS, there are visualization tools within AISAP that allow users to display vessel

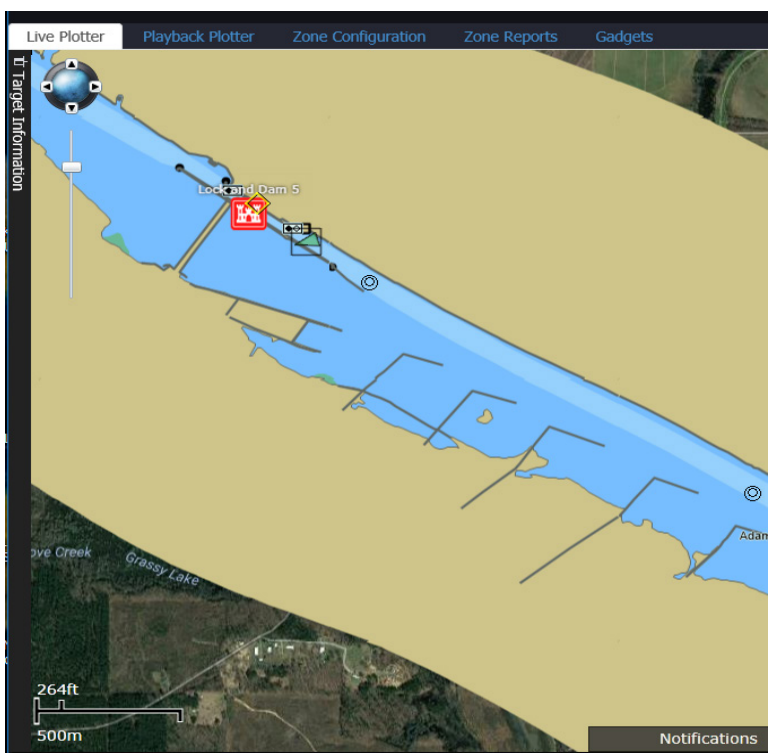

Figure 1. LOMA user interface showing live feed of a vessel (green triangle) at Lock and Dam 5 on the Arkansas River. (Credit: LOMA/USACE ERDC-CHL) track line maps (point to point connections) and signal density plots; for examples see Figure 2. Other AISAP functions include statistical summaries of vessel characteristics and downloadable spreadsheet files for information such as dwell time within an area or vessel speed across a userdefined digital gate.
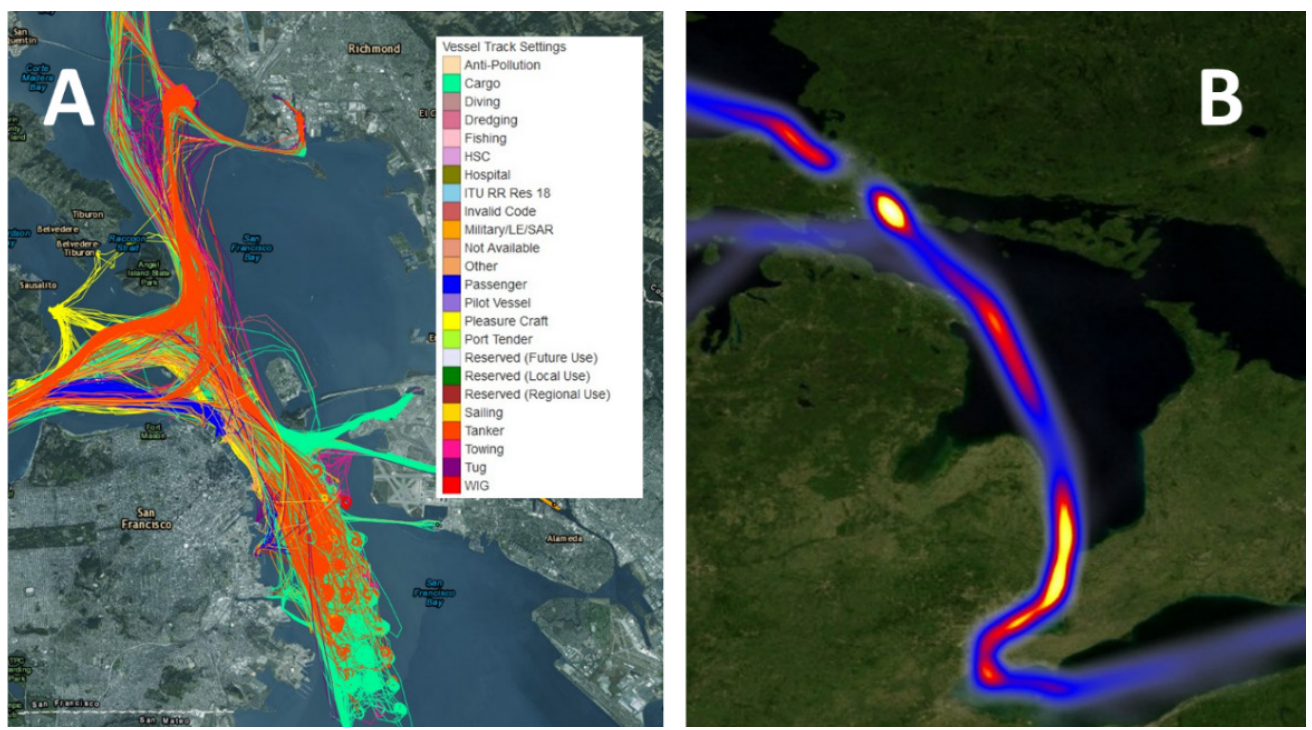

Figure 2. (A) Historical vessel tracks in San Francisco Bay; (B) AIS signal density plot along the eastern coast of Michigan and the Soo Locks. (Credit: AISAP/USACE ERDC-CHL)

Real-Time Operational Use. Within the USACE, one of the primary real-time operational uses of AIS data is through the LOMA system. LOMA allows users the ability to set up zones and receive notices any time a vessel enters or exits that zone (Figure 3 ). This provides lock 
operators with an estimated arrival time for approaching vessel traffic and allows them to plan accordingly. Data on vessels entering and exiting zones are stored in a database and can be retrieved and downloaded for further analysis. LOMA also has the ability to play back saved AIS data up to 45 days old for use in incident investigation or to observe recent waterway usage. This capability has been used to determine exactly where a reported grounding has occurred, saving the cost and effort of dispatching survey teams when the grounding location is outside the maintained channel.

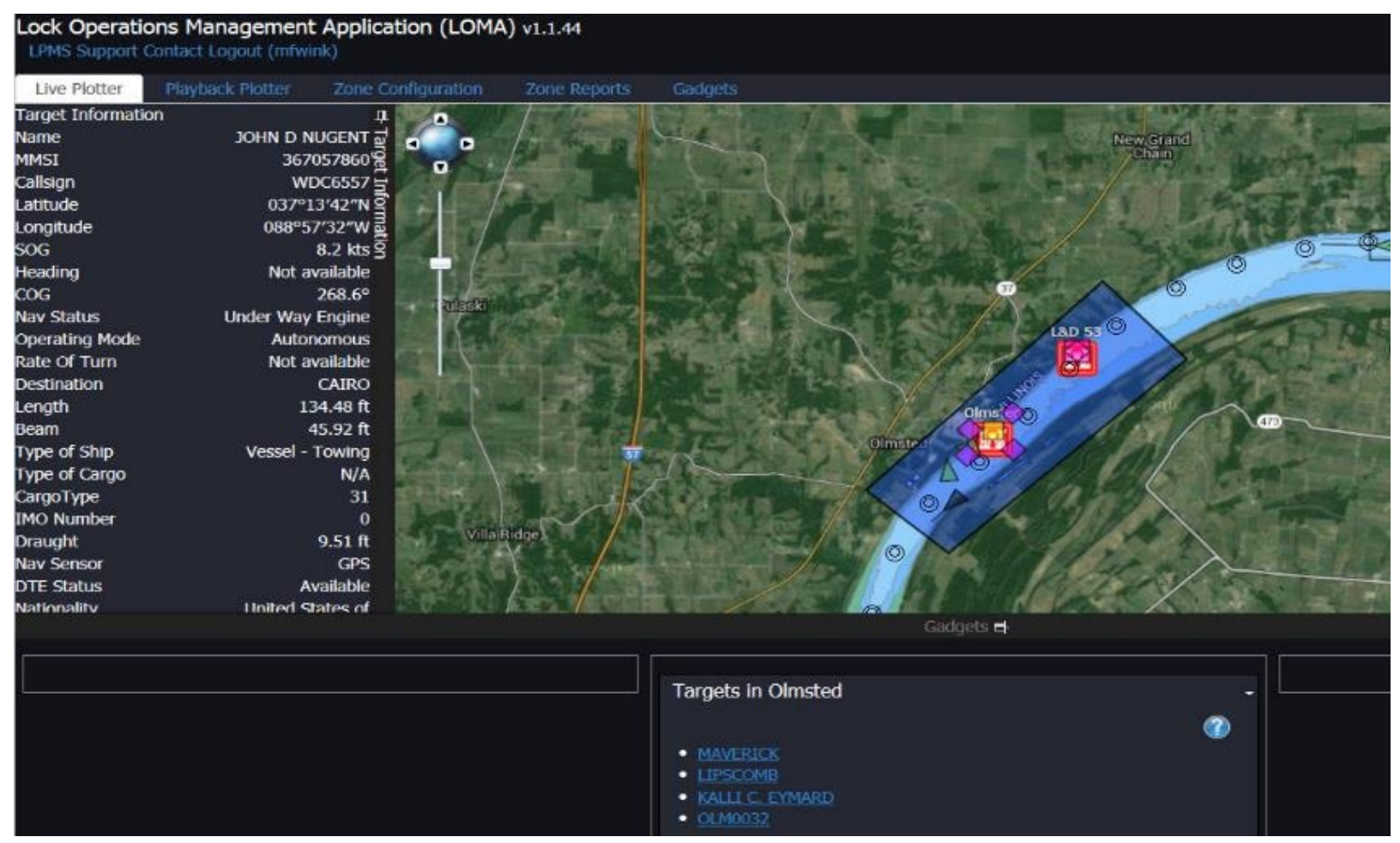

Figure 3. Screenshot of LOMA display showing the user-created watch zone (blue rectangle) and items within that zone, including locks and active vessels such as the John D. Nugent whose information is displayed in the left panel. (Credit: LOMA/USACE ERDC-CHL) 
Another example of real-time operational support provided by AIS is the ability to transmit information to vessels. For example, AIS data feeds can be used to transmit information about shifting work zones around equipment such as the USACE Mat Sinking Unit that operates along the Mississippi River, or operational changes including alternate routes that might be available during high water levels on a river. Another application of this is the ability to generate a virtual aid to navigation (AtoN) before a physical buoy can be placed or in places where the presence of ice or large tidal ranges prevent placement of a physical buoy or other type of AtoN. An example of this is shown in Figure 4, where a virtual AtoN is marking a submerged wreck along an inland waterway. The AIS transmit

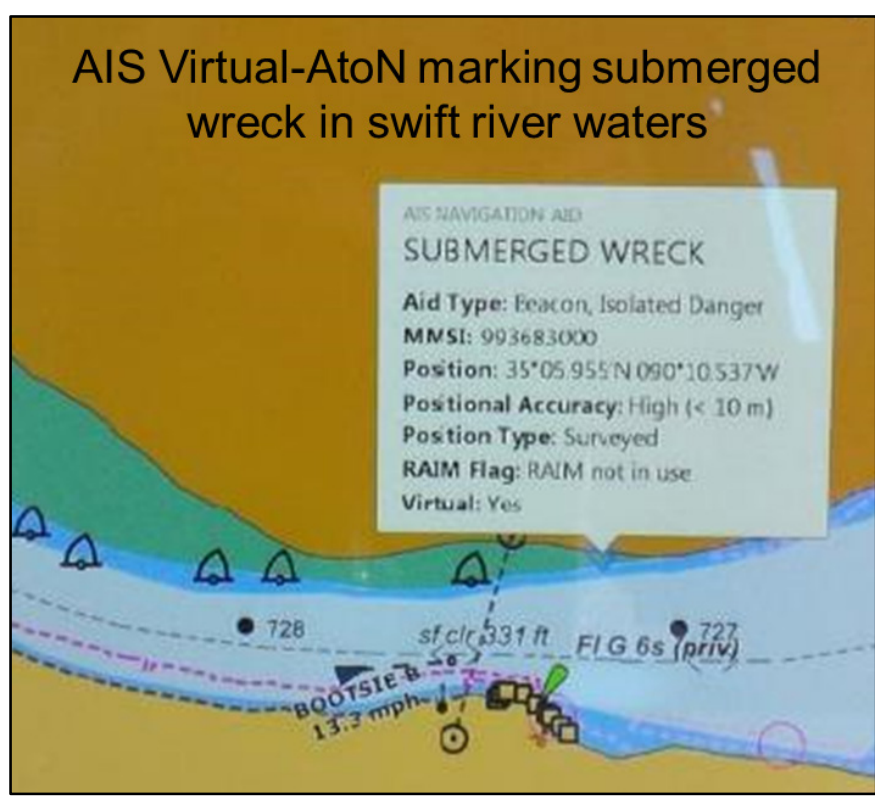

Figure 4. Example of AIS broadcasting a virtual aid to navigation (AtoN) in a location where swift moving water prevents buoy placement. (Credit: LOMA/USACE ERDC-CHL) capability could also be used to relay weather observations, water levels, or traffic plans for navigation locks. Protocols for information transmissions are being developed in partnership with the USCG.

\section{Waterway Incident Investigations.}

Waterway incidents might happen in remote locations, and depending on the type of incident, may be reported days later or not officially reported at all and only relayed through informal means of communication. For example, a tow pilot reported a grounding event inside of the channel near River Mile 819 of the Upper Mississippi River near a notoriously sharp bend in the river. A recreation of the vessel track line (Figure 5) using AIS data showed that the grounding likely happened just outside of the marked channel, which meant the local USACE St. Paul District did not have an urgent need to dispatch a hydrosurvey team to identify a shoal formation.

A similar situation occurred in the

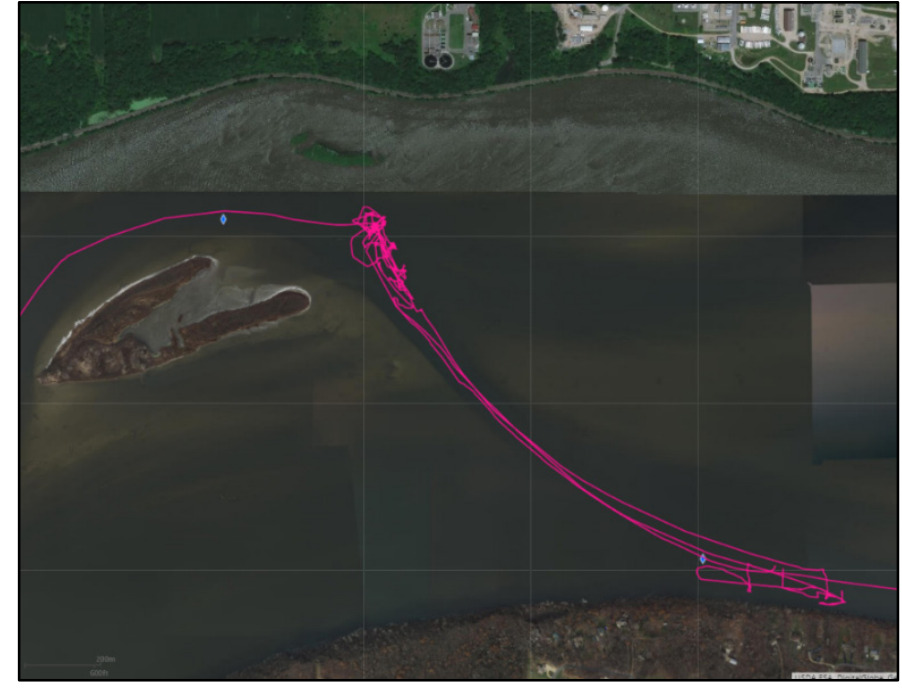

Figure 5. Recreated vessel trackline (pink) from a reported grounding near a sharp turn in the Upper Mississippi River near River Mile 819. Blue diamonds represent mile markers. (Credit: AISAP/USACE ERDCCHL, USACE St. Paul District)

USACE Norfolk District where a grounding inside the navigation channel was informally reported. 
In this case, the re-created vessel track line was overlain on recent bathymetric data from a hydrosurvey (Figure 6) which suggested that there was a shoal forming in the reported location but that the channel was still navigable. A third example of the AIS data use for incident analysis is shown in Figure 7, which depicts re-created tracklines from an incident where two vessels crossed paths on the Columbia River within 10 minutes of each other. Although there was no accident associated with this situation, capturing such near-miss events can provide valuable information for waterway managers or users.

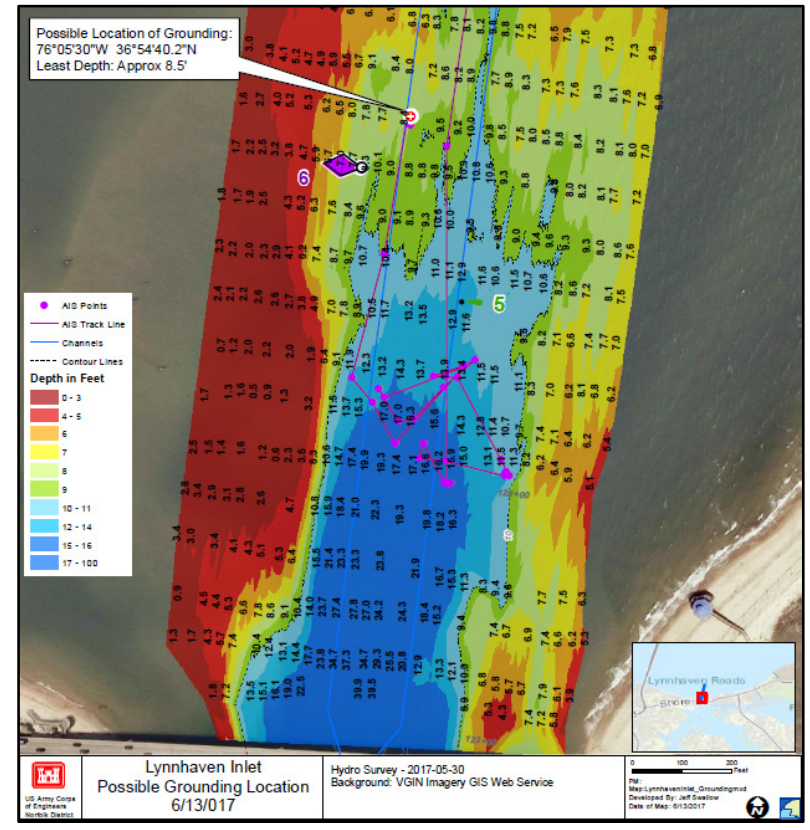

Figure 6. Vessel track from reported grounding (purple line) over contour lines from a hydrosurvey. (Credit: USACE Norfolk District)

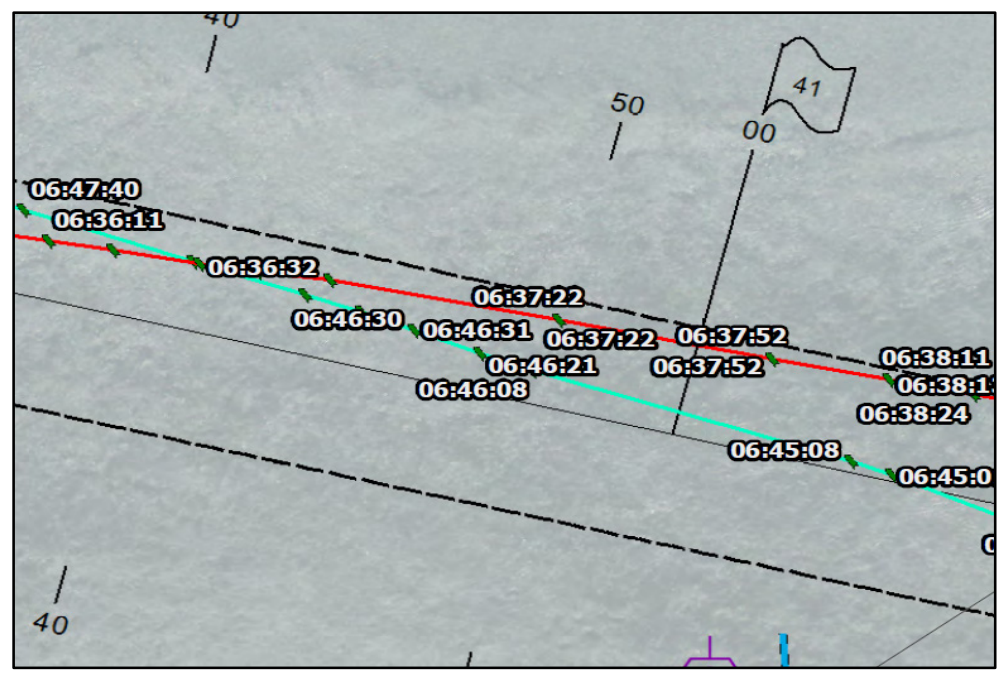

Figure 7. Forensic analysis of reported "near miss" where vessels crossed paths but did not collide while underway in the Columbia River. (Credit: USACE Portland District) 
Waterway Use Analysis. In addition to the real-time operational support and utility during maritime incident investigations, AIS data have proven useful in a variety of waterway use analysis projects.

Sturgeon and vessel interaction in James River, Virginia. AIS data have recently been used to evaluate the potential for interactions between vessels and aquatic species of concern within the USACE Norfolk District. The James River flows through Virginia and contains endangered sturgeon species. By combining fish-movement tracking data (collected with acoustic tags) and AIS vessel position data, the District is investigating how fish behave when in close proximity to large moving vessels (Balazik et al. 2018). Figure 8 shows an example of the timestamped and georeferenced AIS and sturgeon-position data sets displayed together.

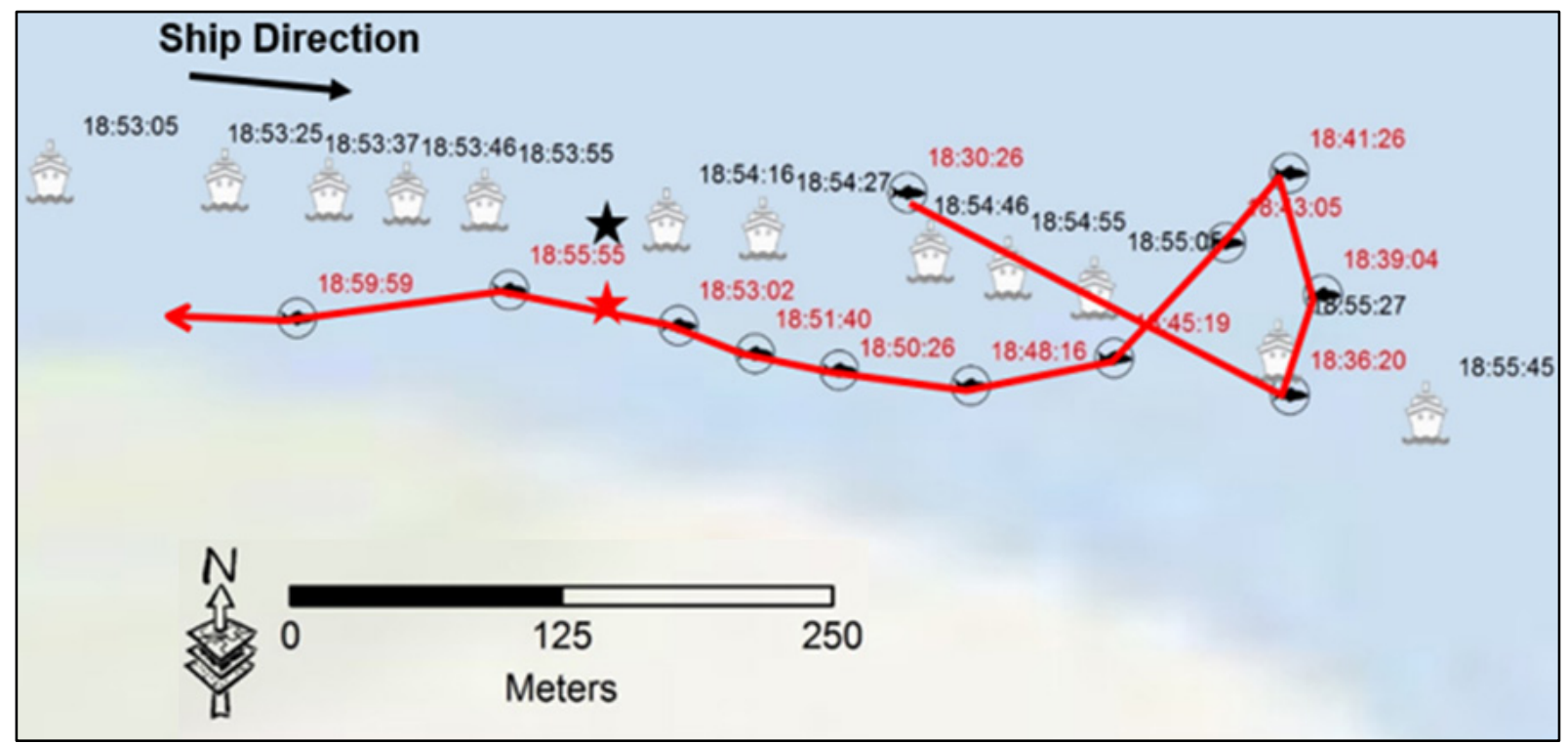

Figure 8. Vessel position location (ship icons) and acoustic-tagged sturgeon tracks (fish icons connected by red line) in the James River, VA. (Credit: M. Balazik [USACE-ERDC-EL])

Great Lakes maritime transportation and the steel industry. The USACE Detroit District has used AISAP to extract vessel position reports for dry bulk commodity vessels transiting throughout the Great Lakes system. With those position reports, staff at Detroit District developed a signal density (heatmap) layer and then combined that imagery with land-side information about strategic industrial facilities in the region. The resulting graphic (Figure 9) is used to illustrate the important relationship between waterborne transportation of iron ore from mines along the edge of Lake Superior to steel mills in states around the Great Lakes region. 


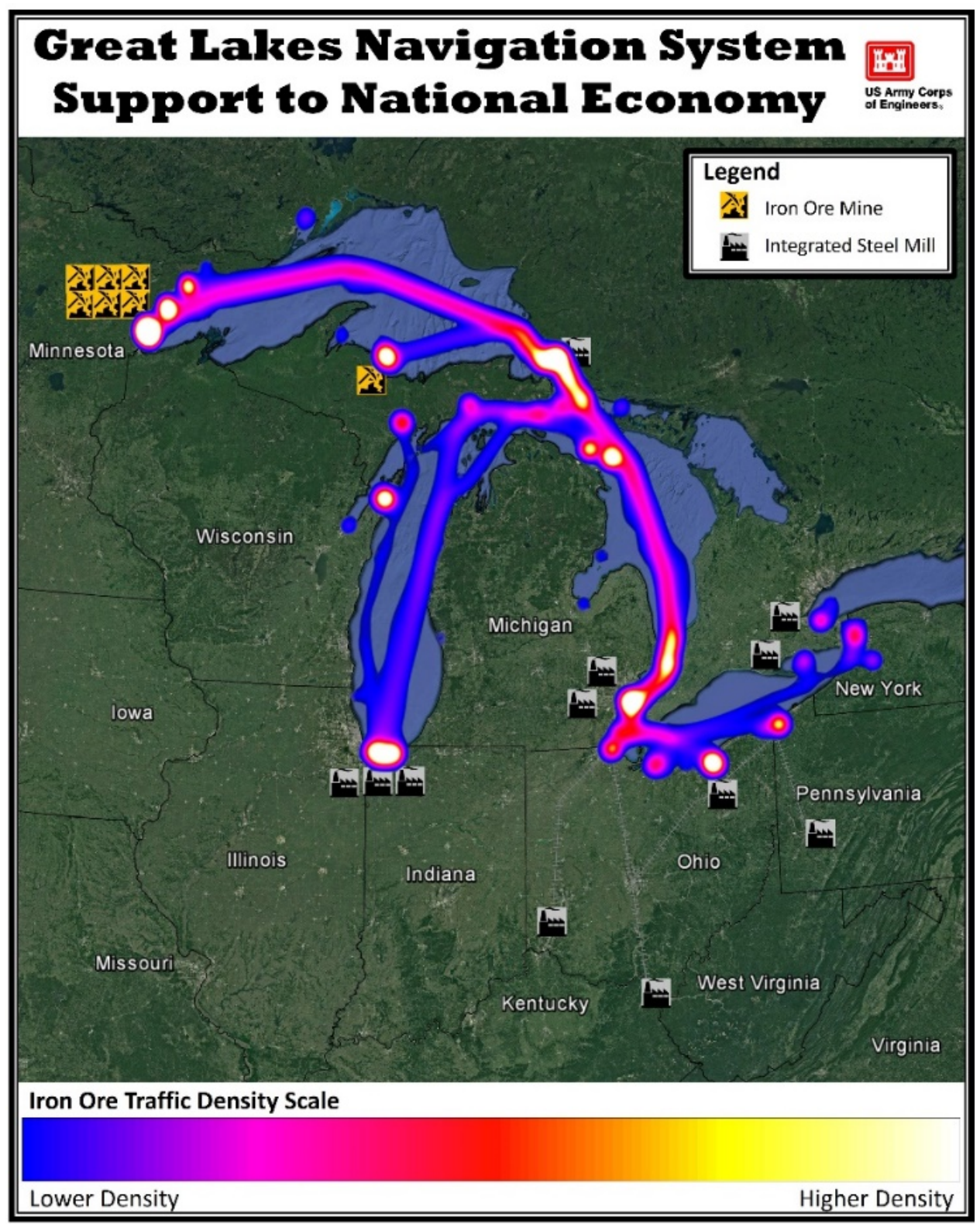

Figure 9. Informational graphic showing the interaction between waterborne transportation, iron ore mines, and the steel industry in the Great Lakes region. (Credit: USACE Detroit District)

Fleeting areas on the Mississippi River. As part of research into potential river training structures, staff in the USACE St. Louis District acquired multiple years of historic AIS vessel position reports for a portion of the Mississippi River. Figure 10 shows position reports by month from January through December 2015, revealing a year of traffic that utilized the main navigation channel as well as designated fleeting areas (shown as red polygons in Figure 10). The unexpected finding from plotting this historic AIS data was the revelation of previously unknown barge fleeting activity areas, represented as the multi-color cluster of points above the marker for River Mile 171 in Figure 10. Findings from multiple areas along the Mississippi River informed staff about existing commercial vessel utilization patterns and areas to avoid for construction 
consideration. More details about this study are available in AIS Data Case Study: St. Louis Area Commercial Vessel Fleeting Activity and Potential River Training Structures by Tabbert et al. (2020).

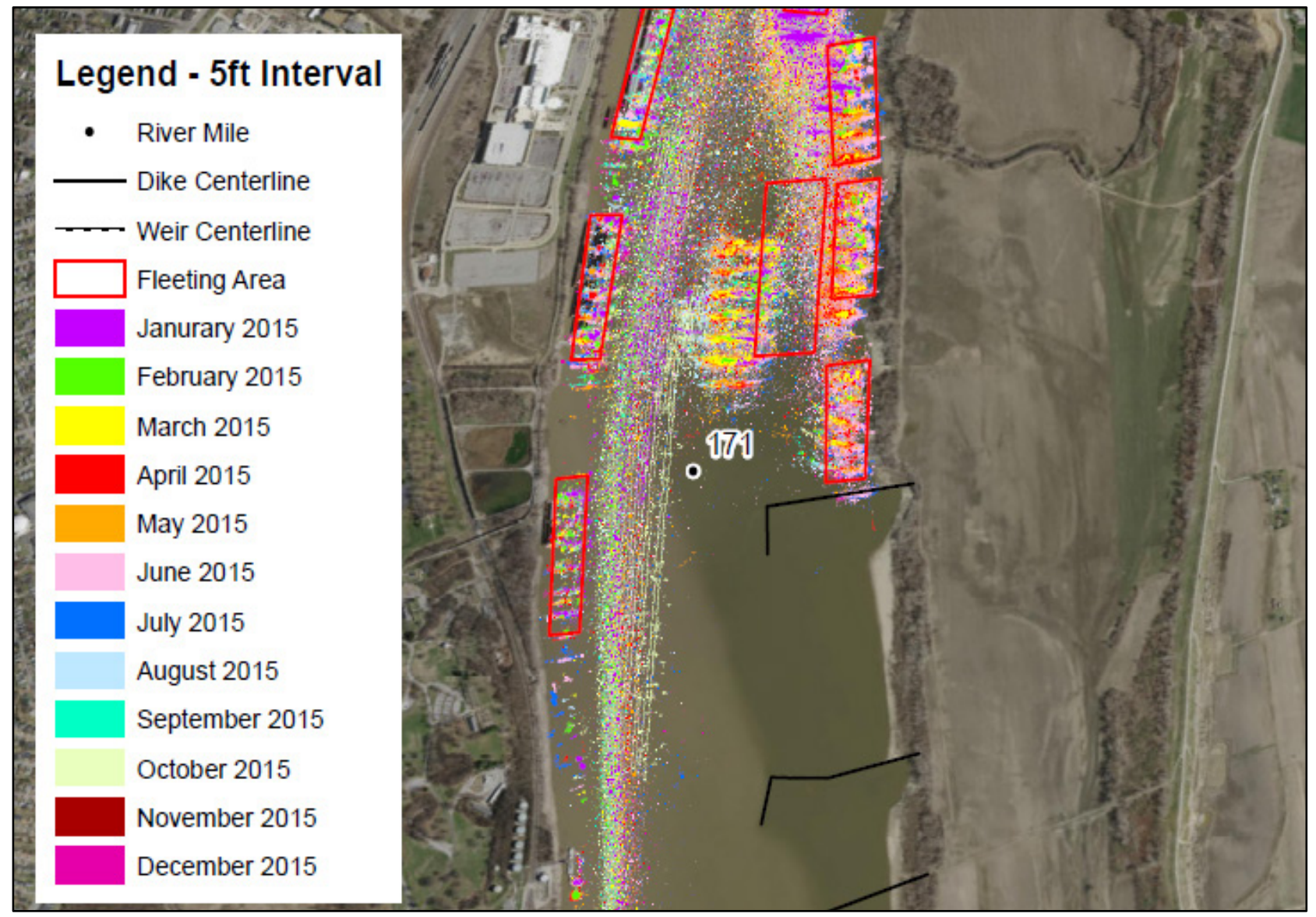

Figure 10. Historic AIS data (multi-color dots) used to identify fleeting activities outside of known designated areas (red boxes). River Mile Marker 171 in center. (Credit: USACE St. Louis District, Applied River Engineering Center)

RESULTS: The examples described above show how AIS capabilities and data contribute to realtime waterway operations, incident investigations, and historical waterway use analysis across the USACE. These examples are not all encompassing but rather represent a subset of exemplar use cases. The value of this information for decision-making purposes has not been formally quantified. However, the expanding user base for the LOMA software within USACE, and for the AISAP software within USACE and across other partner federal agencies (including the USCG, National Oceanic and Atmospheric Administration, Department of Homeland Security, and Department of Transportation), indicates there is a substantial demand for AIS data to answer a variety of questions about how America's waterways are being used. Figure 11 shows a recent map of AIS transceiver locations and estimated transmit/receive coverage extent for coastal and inland regions, including AIS towers maintained by the USCG and other partner organizations. This map, and the authors' experience, shows that there are still coverage gaps in coastal areas and along inland waterways that serve commercial interests. Installing additional transceivers to provide seamless AIS coverage would likely benefit commercial users, infrastructure managers, and researchers with an interest in commercial navigation. 


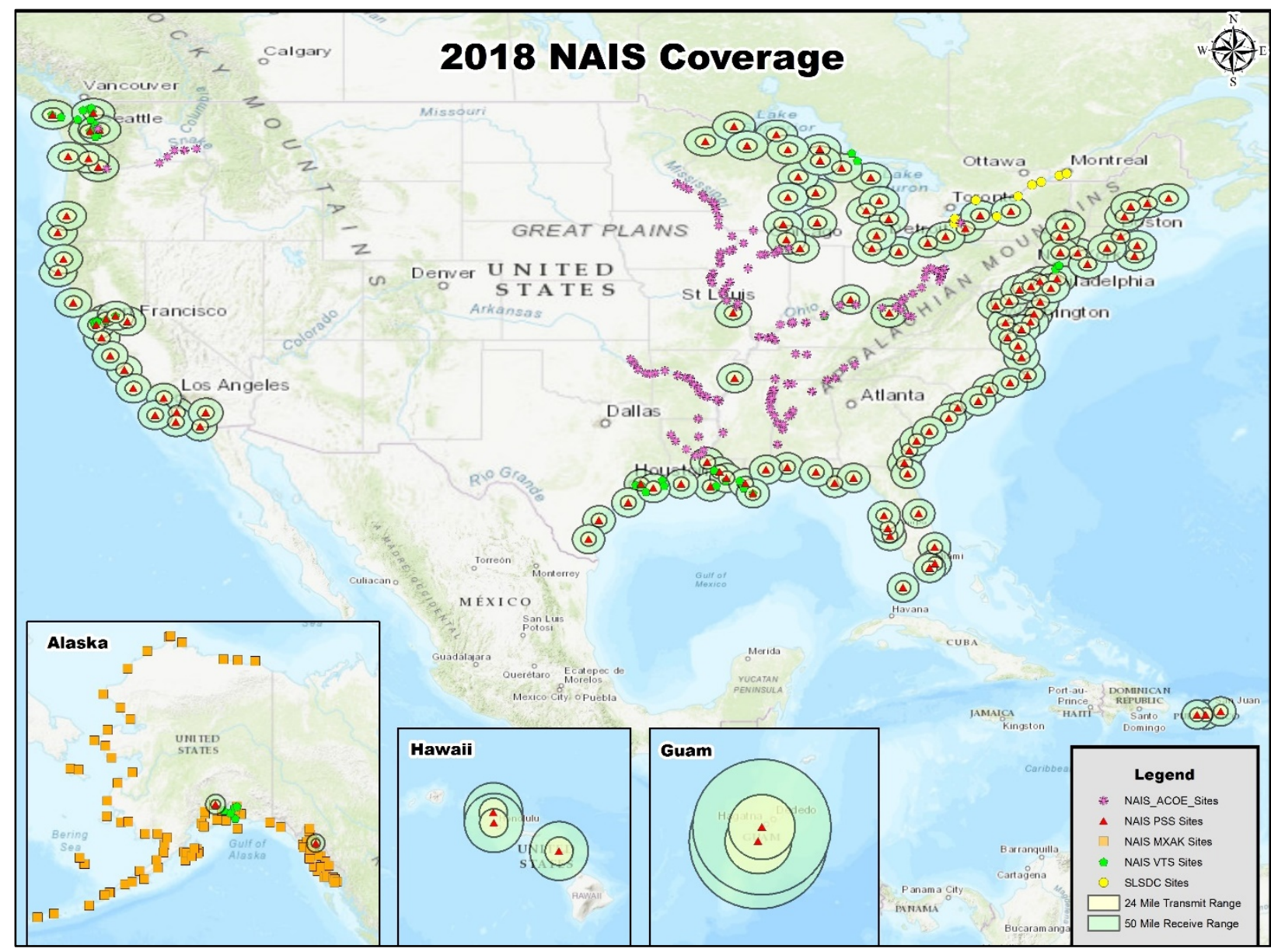

Figure 11. Map of NAIS landside towers and approximate transmit/receive ranges. Abbreviations used for NAIS tower owners: ACOE, Army Corps of Engineers; PSS, Primary Shoreside (USCG); MXAK, Marine Exchange of Alaska; VTS, Vessel Traffic Service; SLSDC, St. Lawrence Seaway Development Corporation. (Credit: USCG)

ADDITIONAL INFORMATION: This CHETN was prepared by Marin M. Kress, Marin.M.Kress@usace.army.mil, ERDC Coastal and Hydraulics Laboratory (ORCiD https://orcid.org/0000-0002-5835-5686). Sincere thanks is given to the users of LOMA and AISAP who have shared their ideas, and especially to L. Whitlow, B. Towne, J. Kilroy, R. Akers, S. Herrle, J. Ratcliff, P. DiJoseph, R. Malburg, M. Wagner, M. Garcia-Diaz, C. Tabbert, M. Booton, J. Swallow, D. Cottrell, the USACE Districts at St. Paul, Norfolk, Detroit, Portland, and St. Louis (notably the Applied River Engineering Center). Special gratitude is extended to the USCG NAIS program. This CHETN is funded by the USACE Navigation Systems Program and should be cited as follows:

Kress, M. M., B. J. Tetreault, K. N. Mitchell, M. Balazik, and M. C. Booton 2020. AIS Data: Real-Time Operation Support, Incident Investigations, and Waterway Use Analysis. ERDC/CHL CHETN-IX-53. Vicksburg, MS: US Army Engineer Research and Development Center. http://dx.doi.org/10.21079/11681/36395 


\section{REFERENCES}

Balazik, M., M. Barber, S. Altman, G. Garman. 2018. "Utilizing Telemetry to Elucidate Adult Atlantic Sturgeon React to Ships and Active Dredging in the James River, VA." Conference Proceedings. American Fisheries Society 148th Annual Meeting. Atlantic City, NJ. https://afs.confex.com/afs/2018/meetingapp.cgi/Paper/31315

IALA (International Association of Marine Aids to Navigation and Lighthouse Authorities). 2008. Establishment of AIS as an Aid to Navigation: Report ID 1062. https://www.iala-aism.org/product/establishment-of-ais-as-an-aidto-navigation-1062/

IEC (International Electrotechnical Commission). 2001. EC 61993-2: 2001-12 Maritime Navigation and Radiocommunication Equipment and Systems - Automatic Identification Systems (AIS) - Part 2: Class A Shipborne Equipment of the Universal Automatic Identification System (AIS) - Operational and Performance Requirements, Methods of Test and Required Test Results. (Technical standards report). https://www.iec.ch/index.htm

ITU-R (International Telecommunications Union - Radiocommunication Sector). 2014. Recommendation ITU-R M.1371: Technical Characteristics for an Automatic Identification System Using Time Division Multiple Access in the VHF Maritime Mobile Frequency Band. Report. https://www.itu.int/rec/R-REC-M.1371/en

Mitchell, K. N., and B. N. Scully. 2014. "Waterway Performance Monitoring via Automatic Identification System (AIS) Data." Transportation Research Record: Journal of Transportation 2426 (1): 20-26. https://doi.org/10.3141/2426-03

PIANC (The World Association for Waterborne Transport Infrastructure). 2019. Guidelines and Recommendations for River Information Services. InCom Working Group Report Number 125/I-2019. https://www.pianc.org/publications/inland-navigation-commission/wg125-1

Scully, B., and K. N. Mitchell. 2015. Archival Automatic Identification System (AIS) Data for Navigation Project Performance Evaluation. ERDC/CHL CHETN-IX-40. Vicksburg, MS: US Army Engineer Research and Development Center. http://hdl.handle.net/11681/2066

Tabbert, C., J. Vest, A. Rhoads, D. Myers, T. Lauth, E. Brauer, J. Wallace, D. Gordon, and M. Kress. 2020. AIS Data Case Study: St. Louis Area Commercial Vessel Fleeting Activity and Potential River Training Structures. ERDC/CHL CHETN-IX-52. Vicksburg, MS: US Army Engineer Research and Development Center. http://dx.doi.org/10.21079/11681/36334

USACE-ERDC (US Army Corps of Engineers, US Army Engineer Research and Development Center). 2017. Lock Operations Management Application (LOMA). Software package. https://loma.usace.army.mil

USACE-ERDC (US Army Corps of Engineers, US Army Engineer Research and Development Center). 2018. AIS Analysis Package (AISAP). Software package. https://ais-portal.usace.army.mil

USCG (US Coast Guard). 2018. Navigation Center: Automatic Identification System Overview. http://www.navcen.uscg.gov/?pageName=AISmain

US Code of Regulations. 2019. Title 33-Navigation and Navigable Waters. "Part 164-Navigation Safety Regulations." 33 C.F.R. § 164.46. Washington, DC. https://www.govinfo.gov/content/pkg/CFR-2019-title33-vol2/xml/CFR2019-title33-vol2-part164.xml

NOTE: The contents of this technical note are not to be used for advertising, publication or promotional purposes. Citation of trade names does not constitute an official endorsement. 